Research Article

\title{
Return Decision Model of the Manufacturer-Leading Dual-Channel Supply Chain
}

\author{
Xuelong Zhang $\mathbb{D}^{1,2}$ Hui Wang, ${ }^{1}$ Xiangzhong $\mathrm{Zhao}^{1}$ and Doudou $\mathrm{Wu}^{1}$ \\ ${ }^{1}$ Schoold of Business, Guilin University of Electronic Technology, Guilin 541004, China \\ ${ }^{2}$ Guangxi Aviation Logistics Research Center, Guilin 541004, China \\ Correspondence should be addressed to Xuelong Zhang; zhxl2008@guet.edu.cn
}

Received 9 September 2020; Accepted 13 November 2020; Published 1 December 2020

Academic Editor: Gonglin Yuan

Copyright (c) 2020 Xuelong Zhang et al. This is an open access article distributed under the Creative Commons Attribution License, which permits unrestricted use, distribution, and reproduction in any medium, provided the original work is properly cited.

\begin{abstract}
According to the manufacturer-leading dual-channel supply chain return problem, a linear demand function considering the change rate of product interaction between the two channels and the change rate of market demand on the return price was established. Under the premise of no cross-return, this paper analyzes the changes of the optimal profit value of the manufacturer, retailer, and supply chain of the dual-channel supply chain in the context of centralized and decentralized decision-making and through the establishment of the price discount decision model and compensation strategy to coordinate the whole supply chain profit. This paper has shown that the use of the price discount decision model and compensation policy model could make the whole supply chain profit optimum value in decentralized decision-making situations equal to profit optimum value in the centralized decision-making situations, and price discount model could make manufacturers better to maximize profit considering the same return scenario, and that compensation policy model could be more helpful to maximize profits for retailers.
\end{abstract}

\section{Introduction}

With the acceleration of commodity informationization, many e-commerce platforms (Taobao, Jingdong, Vipshop and Dangdang) have launched "shopping carnival" and other marketing activities, which not only make the number of goods purchased online greatly increase but also bring into the public eye a large number of intractable return problems arising from transaction activities. Influenced by information asymmetry of commodity transaction, subjective factors of consumers, distribution and transportation of commodities, etc., the return rate of goods purchased online keeps rising. Return processing has become one of the most important links in enterprise operation management. Scholars at home and abroad have carried out a lot of relevant research studies in order to improve the efficiency of enterprise operation management.

According to the dominant position of supply chain members in the supply chain, domestic and foreign scholars study the return problem from two main bodies: manufacturer and retailer. As for the manufacturer-led supply chain, Mukhopadhyay and Setaputra [1] studied the optimization of return in a single-channel supply chain where only manufacturers provided return policies. Samar and Mukhopadhyay [2] focused on manufacturers and discussed the formulation of return policies, changes in manufacturers' profits, and product repurchase. Lee [3] studied that when the manufacturer is the market subject, the market demand of consumers will fluctuate with the preferential rate of return policy provided by the manufacturer. The higher the preferential rate, the greater the market demands. As for the retailer-dominated supply chain, Taleizadeh et al. [4] studied optimal pricing and alliance selection decision-making in the supply chain dominated by retailers considering return policies.

In response to the return policies, channels, and other issues; Zaarour et al. [5] established a mathematical model to explore the functional relationship between the product return rate and the optimal collection period in a closed-loop supply chain, which was one of the earliest papers to solve the problem of the reverse logistics network.

Melachrinoudis and Png [6] found out the best time to adopt the return strategy and the corresponding return 
strategy at that time to obtain the best benefit through the framework analysis of the return scenario. Ofek et al. [7] mainly studied the changes in the service level, pricing, and return rate of retailers when there were only two competing traditional retailers in the market and discussed whether it was necessary to establish return policies in online channels. Pasternack [8] studied the coordination problem of channel return and proved that it was not the best strategy for suppliers to adopt all buybacks or all rejections for retailer return by quantitative analysis, and buyback coordination should be carried out according to the return ratio. Genc and De Giovanni [9] studied the impact of return behavior on supply chain revenue in the closed-loop supply chain according to price and rebate. Mahmoodi and Ohmori [10] established the return process management and incentive mechanism of the supply chain in consideration of the high variability of return quantity and conditions in the closed-loop supply chain. Noori-daryan and Taleizadeh [11] built a three-level supply chain model and proved that return contracts among members of the supply chain could bring more profits to the supply chain. Taleizadeh et al. [12] studied the single-channel and dual-channel return strategy, and the results showed that the dual-channel strategy was more beneficial to the supply chain, and the more generous the return policy, the higher the overall profit. Radhi and Zhang [13] studied the same-channel and cross-channel return strategies of dual-channel retailers, established a mathematical model to determine the optimal order volume, and put forward some opinions on different cross-channel return policies. Yoo [14] studied the relationship between return policies and product quality decisions in decentralized systems based on different risk attitudes of suppliers. Masoudipour et al. [15] established a closed-loop supply chain model based on return quality, and the results showed that the improvement of return rate of low- and medium-quality products would bring higher profits. In addition, the study of return policy can also be combined with intelligent algorithms. Amodeo and Godichaud [16] integrated returned products into the traditional supply chain process and proposed a supply chain model based on simulation and multiobjective optimization to optimize the control strategy of the multistage supply chain.

The research of the above scholars focused on the coordination of single-channel and dual-channel returns by establishing a model to calculate the optimal order quantity and return quantity, but they did not conduct a specific study on return profit. This paper mainly studies the return decision problem of the manufacturer-led dual-channel supply chain and establishes two return decision models of price discount and compensation strategy, respectively. By analyzing and demonstrating the optimal value changes of each decision variable of the two models, the optimal decision application model is obtained to improve the overall profit and decision effect of the dual-channel supply chain.

\section{Models and Assumptions}

The manufacturer will distribute the goods after receiving the supply from the supplier, and its structure is shown in Figure 1. The offline channel manufacturer wholesales the goods to the retailer at unit price $w$, and the retailer sells the goods to the online customer $C_{r}$ at unit price $p_{r}$; then, the offline distribution activity of the manufacturer ends. The manufacturer of the online channel sells the goods directly to the customer $C_{d}$ at the unit price $p_{d}$ to complete the distribution activity. The increase of return rate makes the distribution activities involve the return process. This paper assumes that all goods can only be returned according to the original sales channel. When customer $C_{r}$ returns the goods, it will first apply for the return to retailer $R$ at unit price $t_{r}$ and then return the products to supplier $S$ through manufacturer $M$. When customer $C_{d}$ returns the product, it shall directly submit the product to manufacturer $M$ at unit price $t_{d}$.

For the convenience of model calculation, all symbols and meanings referenced in this paper are shown in Table 1.

\section{Basic Return Decision Models of the Dual- Channel Supply Chain}

It is assumed that the demand function of both online and offline channels is a linear relation function that only considers the influence of sales price and return price. Moreover, the quantity demanded is inversely proportional to the commodity price of the channel and is directly proportional to the return price of the channel. For the convenience of calculation, set $\alpha=\alpha_{r}=\alpha_{d}$, and establish the demand function of the two-channel supply chain as follows:

demand function of offline retail channels:

$$
D_{r}=s a-\alpha_{r} p_{r}+\beta t_{r}
$$

demand function of online direct sales channel:

$$
D_{d}=(1-s) a-\alpha_{d} p_{d}+\beta t_{d}
$$

Since the convenience of offline return is relatively high, it is assumed that the return quantity is the base value; then, the return function of the offline retail channel is

$$
R_{r}=b \text {. }
$$

The return of online direct sales channels is affected by a variety of factors. Due to consumers' personal self-interest, assuming that there is a certain amount of return and there is a positive correlation with the online return price, the return function of the online direct sales channel is expressed as

$$
R_{d}=b+\psi t_{d}
$$

According to the calculation method of profit, it can be concluded that

$$
\begin{aligned}
& \text { profit function of offline retail channels: } \\
& \qquad \pi_{r}=\left(p_{r}-w\right) \times D_{r}-R_{r} \times t_{r}+R_{r} \times v
\end{aligned}
$$

profit function of online direct sales channel:

$$
\pi_{d}=\left(p_{d}-c\right) \times D_{d}+(w-c) \times D_{r}-R_{d} \times t_{d}+R_{d} \times v .
$$




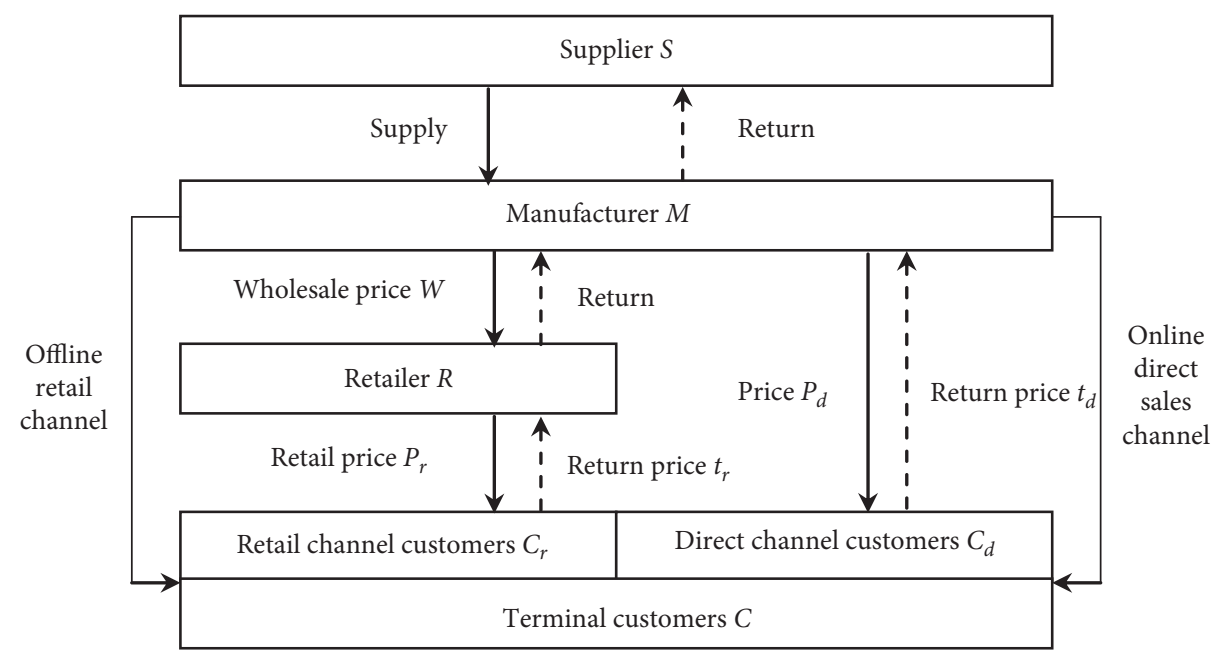

FIgURE 1: Return structure diagram of manufacturer's dominant dual-channel supply chain.

TABle 1: Model symbol description and meaning.

\begin{tabular}{|c|c|}
\hline Symbol & Symbol description and interpretation \\
\hline$s$ & Product purchase loyalty coefficient of offline retail channel customers \\
\hline $1-s$ & Product purchase loyalty coefficient of online direct sales channel customers \\
\hline$a$ & Potential market demand \\
\hline$P_{r}$ & Retailer's sales prices in the offline retail channels \\
\hline$P_{d}$ & Manufacturer's sales prices in the online direct marketing channels \\
\hline$\alpha$ & The change rate of product interaction between two channels \\
\hline$\beta$ & The change rate of dual-channel market demand with product return price \\
\hline$D_{r}$ & Demand for products from offline retail channels \\
\hline$D_{d}$ & Customer demand for products of online direct marketing channels \\
\hline$\pi_{\mathrm{r}}$ & Retailer's profit \\
\hline$\pi_{d}$ & Manufacturer's profit \\
\hline$w$ & Wholesale price of products from the manufacturer to the retailer \\
\hline Superscript $z$ & Price discount contract model \\
\hline$c$ & The manufacturer's unit cost of production \\
\hline$t_{r}$ & Return prices for offline retail channels \\
\hline$t_{d}$ & Return prices for direct online sales channels \\
\hline$R_{r}$ & Total return volume of offline retail channels \\
\hline$R_{d}$ & Total return volume of online direct sales channel \\
\hline$b$ & Basic return quantity of two channels \\
\hline$\Psi$ & The rate of change in product return volume due to changes in return prices in online channels \\
\hline$v$ & The unit salvage value of the returned product \\
\hline Superscript $*$ & Optimal case \\
\hline Superscript $j$ & Centralized decision model \\
\hline Superscript $f$ & Decentralized decision model \\
\hline & Total profit of the supply chain \\
\hline Superscript ${ }^{B}$ & Compensation strategy model \\
\hline
\end{tabular}

The total profit of the supply chain is the sum of the retailer's profit and the manufacturer's profit, which is expressed as

$$
\begin{aligned}
\pi_{T}= & \pi_{r}+\pi_{d}=\left(p_{r}-w\right) D_{r}-R_{r} t_{r}+R_{r} v \\
& +\left(p_{d}-c\right) D_{d}+(w-c) D_{r}-R_{d} t_{d}+R_{d} v .
\end{aligned}
$$

3.1. Centralized Return Decision Models. Centralized decision-making means that online and offline channels cooperate to return goods and jointly formulate return policies to achieve the goal of maximizing the overall profit of the supply chain. The decision model of centralized return is as follows:

$$
\begin{aligned}
\pi^{j}= & \pi_{T}=\pi_{r}+\pi_{d} \\
= & \left(p_{r}-w\right) D_{r}-R_{r} t_{r}+R_{r} v+\left(p_{d}-c\right) D_{d} \\
& +(w-c) D_{r}-R_{d} t_{d}+R_{d} v \\
= & \left(p_{r}-c\right)\left(s a-\alpha_{r} p_{r}+\beta t_{r}\right) \\
& +\left(p_{d}-c\right)\left[(1-s) a-\alpha_{d} p_{d}+\beta t_{d}\right] \\
& -b t_{r}-\left(b+\psi t_{d}\right) t_{d}+v\left(R_{r}+R_{d}\right) .
\end{aligned}
$$


The Hessian matrix of formula $(8)$ is $\left[\begin{array}{cccc}0, & 0, & \beta, & 0 \\ 0, & 0, & 0, & \beta \\ \beta, & 0, & -2, & 2 \alpha \\ 0, & \beta, & 2 \alpha, & -2\end{array}\right]$, and the value of the Hessian matrix is equal to $-\beta^{4}$. Since the Hessian matrix is negative, there is an optimal value of profit.
In formula (8), the first partial derivatives of $\pi^{j}$ with respect to $p_{r}$ and $p_{d}$ are obtained, respectively. By setting the partial derivative to zero, we can obtain the optimal selling price of retailers and manufacturers under the centralized decision:

$$
\left\{\begin{array}{l}
p_{r}^{*}=\frac{b+c \beta}{\beta} \\
p_{d}^{*}=\frac{b \beta^{2}+c \beta^{3}-4 b \alpha \psi-2 a \beta \psi-2 c \beta \psi+2 a s \beta \psi-2 c \alpha \beta \psi+v \beta^{2} \psi}{A \beta} .
\end{array}\right.
$$

By calculating the first derivative of $\pi_{j}$ for $t_{r}$ and $t_{d}$ in formula (8) and making it zero, the optimal return price of retailers and manufacturers can be obtained:

$$
\left\{\begin{array}{l}
t_{r}^{*}=\frac{2(1-\alpha) b \beta^{2}+(c-a s-c \alpha) \beta^{3}-8\left(1-\alpha^{2}\right) b \psi-4(c-(s+\alpha-s \alpha) a) \beta \psi+2 c \mathrm{H}-2 v \alpha \beta^{2} \psi}{A \beta^{2}}, \\
t_{d}^{*}=\frac{2 b-2 b \alpha-a \beta+c \beta+a s \beta-c \alpha \beta+2 v \psi}{A} .
\end{array}\right.
$$

The optimal demand of retailers and manufacturers can be obtained by substituting formula (9) into formula (8):

$$
\left\{\begin{array}{l}
D_{r}^{*}=\frac{\alpha \beta \psi[2 a(1-s)+2 c(\alpha-1)-v \beta]+b(\alpha-1)[4 \alpha \psi-\mathrm{H}]}{A \beta} \\
D_{d}^{*}=\frac{b \beta(1-\alpha)+\psi[2 c+2 a(s-1)-2 c \alpha+v \beta]}{A}
\end{array}\right.
$$

By substituting formulas (9)-(11) into formula (8), the optimal profit of the supply chain under centralized decision-making can be obtained as follows:

$$
\begin{aligned}
p_{j}^{*}= & \frac{1}{A \beta^{2}}\left(-2 b^{2} \beta^{2}+2 b^{2} \alpha \beta^{2}+a b \beta^{3}-2 b c \beta^{3}+2 b c \alpha \beta^{3}-2 b v \beta^{4}+4 b^{2} \psi-4 b^{2} \alpha^{2} \psi+4 b c \beta \psi\right. \\
& -4 a b s \beta \psi-4 a b \alpha \beta \psi+4 a b s \alpha \beta \psi-2 b c H-a^{2} \beta^{2} \psi+2 a c \beta^{2} \psi-c^{2} \beta^{2} \psi+2 a^{2} s \beta^{2} \psi \\
& -2 a c s \beta^{2} \psi-a^{2} s^{2} \beta^{2} \psi+6 b v \beta^{2} \psi-2 a c \alpha \beta^{2} \psi+2 c^{2} \alpha \beta^{2} \psi+2 a c s \alpha \beta^{2} \psi+2 b v \alpha \beta^{2} \psi \\
& \left.-c^{2} \alpha^{2} \beta^{2} \psi+a v \beta^{3} \psi-c v \beta^{3} \psi-a s v \beta^{3} \psi+c v \alpha \beta^{3} \psi-v^{2} \beta^{2} \psi^{2}\right) .
\end{aligned}
$$


In formulas (9) (37), $A=\beta^{2}-4 \psi$ and $\mathrm{H}=2 \alpha^{2} \beta \psi$.

To simplify the expression, let

$$
\begin{aligned}
E= & -2 b^{2} \beta^{2}+2 b^{2} \alpha \beta^{2}+a b \beta^{3}-2 b c \beta^{3}+2 b c \alpha \beta^{3}-2 b v \beta^{4}+4 b^{2} \psi-4 b^{2} \alpha^{2} \psi+4 b c \beta \psi \\
& -4 a b s \beta \psi-4 a b \alpha \beta \psi+4 a b s \alpha \beta \psi-2 b c H-a^{2} \beta^{2} \psi+2 a c \beta^{2} \psi-c^{2} \beta^{2} \psi+2 a^{2} s \beta^{2} \psi \\
& -2 a c s \beta^{2} \psi-a^{2} s^{2} \beta^{2} \psi+6 b v \beta^{2} \psi-2 a c \alpha \beta^{2} \psi+2 c^{2} \alpha \beta^{2} \psi+2 a c s \alpha \beta^{2} \psi+2 b v \alpha \beta^{2} \psi \\
& -c^{2} \alpha^{2} \beta^{2} \psi+a v \beta^{3} \psi-c v \beta^{3} \psi-a s v \beta^{3} \psi+c v \alpha \beta^{3} \psi-v^{2} \beta^{2} \psi^{2} .
\end{aligned}
$$

3.2. Decentralized Return Decision Models. In the decentralized decision-making scenario, the dual channels of the supply chain form an antagonistic relationship, and retailers and manufacturers pursue profit maximization, respectively, in the competitive market, resulting in a fragmented situation. In this paper, the manufacturer is regarded as the market leader, and a Stackelberg game model is used to solve the problem. In the decentralized scenario, the two-channel supply chain return model is as follows:

Retailer's profit function expression:

$$
\pi_{r}^{f}=\left(p_{r}-w\right) \times D_{r}-R_{r} \times t_{r}+R_{r} \times v .
$$

Manufacturer's profit function expression:

$$
\pi_{d}^{f}=\left(p_{d}-c\right) \times D_{d}+(w-c) \times D_{r}-R_{d} \times t_{d}+R_{d} \times v .
$$

The second stage of the game is to maximize retailers' profits. The Hessian matrix of formula (14) is $\left[\begin{array}{cc}-2, & \beta \\ \beta, & 0\end{array}\right]$, and the value of the determinant is $-\beta^{2}$, which means that the Hessian matrix is negative, and the retailer has optimal profit. The first derivation of $\pi_{r}^{f}$ about $p_{r}$ in formula (14) is solved, we make it zero, and then

$$
p_{r}^{f}=\frac{a s+w+\alpha p_{d}+\beta t_{r}}{2}
$$

Substituting formula (16) into formulas (1) and (2), the retailer's demand in the dual-channel supply chain can be obtained which is

$$
D_{r}^{f}=\frac{\left(a s+\beta t_{r}\right)(2-\alpha)-\alpha\left(w+\alpha p_{d}\right)}{2} .
$$

Formula (17) is substituted into formula (15) to obtain the first partial derivative of $w, p_{d}$, and $t_{d}$, respectively, and set them to zero, so as to obtain the optimal wholesale price, the optimal online sales price, and the optimal return price in the decentralized scenario:

$$
\left\{\begin{array}{l}
w^{f *}=\frac{\alpha \beta \psi[2 c+v \beta+2 a(s-1)]+b\left[\beta^{2}(1+\alpha)-2 \psi\left(2+\alpha^{2}\right)\right]}{\mathrm{H}} \\
p_{d}^{f *}=\frac{c \alpha \beta-b}{\alpha \beta} \\
t_{d}^{f *}=\frac{-b(1+\alpha)-v \alpha \psi}{2 \alpha \psi} .
\end{array}\right.
$$

By substituting equation (18) into equation (16), the optimal selling price of offline channels can be obtained as follows:

$$
p_{r}^{f *}=\frac{\alpha \beta \psi[2 c+v \beta+2 a(s-1)]+b\left[\beta^{2}(1+\alpha)-4 \psi\right]}{\mathrm{H}} .
$$

First, substitute formula (19) into formula (14), then calculate the first partial derivative of $\pi_{r}^{f}$ with respect to $t_{r}$, and make it zero, so as to obtain the optimal revenue price of offline channels:

$$
t_{r}^{*}=\frac{\left\{\alpha \beta \psi\left[2 c\left(1-\alpha^{2}\right)-2 a(1-s+s \alpha)+v \beta\right]\right\}+b(1+\alpha)\left[\beta^{2}+4 \psi(\alpha-1)\right]}{\mathrm{H} \beta} .
$$


By substituting formula (18) into formula (15), the optimal profit of the manufacturer can be obtained:

$$
\pi_{d}^{f^{*}}=\frac{2 b \alpha \beta \psi[2 a(s-1)-(\alpha-1)(2 c+v \beta)]+v^{2} \alpha^{2} \beta^{2} \psi^{2}+b^{2}\left[\beta^{2}(1+\alpha)^{2}-4 \psi\left(1+\alpha^{2}\right)\right]}{2 \mathrm{H} \beta} .
$$

By substituting formulas (19) and (20) into (14), the optimal profit of retailers can be obtained:

$$
\pi_{r}^{f^{*}}=\frac{-b \alpha \beta \psi\left[2 c-2 a(1-s+s \alpha)-2 c \alpha^{2}+v \beta(1+2 \alpha)\right]-b^{2}\left[\beta^{2}(1+\alpha)+2 \psi\left(\alpha^{2}-2\right)\right]}{\mathrm{H} \beta}
$$

Under the decentralized decision scenario, the overall optimal profit of the supply chain is

$$
\pi_{f}^{*}=\pi_{r}^{f^{*}}+\pi_{d}^{f^{*}}=\frac{b \mathrm{H}[2 a s+2 c(\alpha-1)-3 v \beta]+v^{2} \alpha^{2} \beta^{2} \psi^{2}+b^{2}\left[\beta^{2}\left(\alpha^{2}-1\right)+4 \psi\left(1-2 \alpha^{2}\right)\right]}{2 \mathrm{H} \beta} .
$$

Comparing formulas (12) and (23), we can see that the difference between the centralized decision and decentralized decision is

$$
\begin{aligned}
\Delta \pi= & \frac{b \mathrm{H}[2 a(s-1)-2 c(\alpha-1)+v \beta]\left(4 \alpha \psi-\beta^{2}\right)-\alpha^{2} \beta^{2} \psi^{2}[2 a(s-1)-2 c(\alpha-1)+v \beta]^{2}}{2 A \mathrm{H} \beta} \\
& +\frac{b^{2}\left[-\beta^{4}\left(\alpha^{2}-1\right)-8 \beta^{2} \psi+2 \mathrm{H} \beta(2 \alpha+1)-16 \psi^{2}\left(\alpha^{2}+\alpha^{4}-1\right)\right]}{2 A \mathrm{H} \beta} .
\end{aligned}
$$

\section{Manufacturer-Led Dual-Channel Supply Chain Return Decision Models}

4.1. Price Discount Contract Models. In the manufacturer-led supply chain, it is assumed that the manufacturer pays the appropriate wholesale price to the retailer to promote the retailer's sales to reach a win-win situation. The function of the wholesale price contract is as follows:

$$
w\left(p_{d}\right)=c+\gamma\left(p_{d}-c\right) .
$$

In formula (25), $\gamma$ is the price discount rate, and $0 \prec \gamma<1$ and $c \prec w\left(p_{d}\right) \prec p_{d}$. Substitute formula (25) into the profit function under decentralized decision-making, and then substitute it into formulas (5) and (6) to obtain the profit function of the manufacturer and retailer under the price discount model:

$$
\left\{\begin{array}{l}
\pi_{r}^{z}=\left[p_{r}-w\left(p_{d}\right)\right] \times D_{r}-R_{r} \times t_{r}+R_{r} \times v \\
\pi_{d}^{z}=\left(p_{d}-c\right) \times D_{d}+\left[w\left(p_{d}\right)-c\right] \times D_{r}-R_{d} \times t_{d}+R_{d} \times v .
\end{array}\right.
$$

Similarly, the optimal sales price and return price of retailers and manufacturers can be obtained by the Stackelberg game according to the decentralized decision model: 


$$
\left\{\begin{array}{l}
p_{r}^{z *}=\frac{c+a s-c \gamma+p_{d}(\alpha+\gamma)+\beta t_{r}}{2} \\
p_{d}^{z *}=\frac{\beta^{2}(b+c \beta+v \psi)-4 b \alpha \psi+2 a \beta \psi(s-1)-2 c \beta \psi(\alpha+1)}{A \beta}, \\
t_{r}^{z *}=\frac{2 b \beta^{2}(\alpha-1)+\beta^{3}[a s+c(\alpha-1)]+8 b \psi\left(1-\alpha^{2}\right)+2 \beta \psi\left[2 c\left(1-\alpha^{2}\right)+2 a s(\alpha-1)+\alpha(v \beta-2 a)\right]}{A \beta^{2}} \\
t_{d}^{z *}=\frac{2 b(\alpha-1)+a \beta(1-s)+c \beta(\alpha-1)-2 v \psi}{A}, \\
w^{z *}=c(1-\alpha)+\frac{\alpha \beta^{2}(b+v \psi+c \beta)-4 b \alpha^{2} \psi-2 \mathrm{H} c+2 \alpha \beta \psi[a(s-1)-c]}{A \beta}
\end{array}\right.
$$

Let $p_{r}^{Z^{*}}=p_{r}^{j^{*}}$ and the optimal selling price of the retailer under the price discount model be equal to the optimal selling price of the retailer under the centralized decision; then,

$$
\gamma=\alpha
$$

Substituting formula (28) into formula (25), the optimal wholesale price under the price discount model can be obtained as follows:

$$
w(p d)=c+\alpha\left(p_{d}-c\right) .
$$

By substituting formulas (27)-(29) into formula (26), the optimal profit of manufacturers and retailers under the price discount model can be obtained which is

$$
\left\{\begin{array}{l}
\pi_{r}^{z^{*}}=\frac{1}{A \beta}\left\{\alpha^{2} \beta^{2} \psi^{2}[2 a(s-1)-2 c(\alpha-1)+v \beta]^{2}+b^{2}\left(\alpha^{2}-1\right)\left[\beta^{2}(A-4 \psi)+16 \psi^{2}\left(\alpha^{2}+1\right)\right]\right. \\
+2 a b \mathrm{H}\left(4 \alpha \psi-\beta^{2}\right)+b c \beta(\alpha-1)\left[\beta^{4}-4 \beta^{2} \psi\left(2+\alpha^{2}\right)+16 \psi^{2}\left(1+\alpha^{3}\right)\right] \\
\left.-v b \beta^{2}\left[\beta^{4}-2 \beta^{2} \psi\left(4+\alpha^{2}\right)+8 \psi^{2}\left(2+\alpha^{3}\right)\right]+a b s \beta\left[\beta^{4}+4 \beta^{2} \psi\left(\alpha^{2}-2\right)-16 \psi^{2}\left(\alpha^{3}-1\right)\right]\right\} \\
\pi_{d}^{z^{*}}=\frac{1}{A^{2} \beta^{2}}\left\{-b^{2} \beta^{4}(\alpha-1)^{2}+4 b^{2} \beta^{2} \psi\left(\alpha^{2}-1\right)(2 \alpha-1)-v^{2} \beta^{2} \psi^{2}\left[\beta^{2}\left(1+\alpha^{2}\right)-4 \psi\right]\right. \\
-16 b^{2} \alpha^{2} \psi^{2}-\left[a^{2}(s-1)^{2}+c^{2}(\alpha-1)^{2}-c v \beta(\alpha-1)-a(s-1)(2 c \alpha-2 c-v \beta)\right] \beta^{2} \psi \times(A-4 \psi) \\
+b \beta\left[\beta^{4}+2 \mathrm{H} \beta-4 \beta^{2} \psi(\alpha+1)-16 \alpha \psi^{2}\left(\alpha^{2}-1\right)\right][-a(s-1)+c(\alpha-1)] \\
\left.-b v \beta^{2}\left[\beta^{4}+\mathrm{H} \beta-2 \beta^{2} \psi(\alpha+3)+8 \psi^{2}\left(\alpha-\alpha^{3}+1\right)\right]\right\} .
\end{array}\right.
$$

The overall optimal profit of the supply chain is

$$
\pi^{z^{*}}=\pi_{r}^{z^{*}}+\pi_{d}^{z^{*}}=\frac{E}{A \beta^{2}} .
$$

It can be seen from formula (31) that the overall optimal profit of the supply chain under the price discount model is equal to the overall optimal profit of the supply chain under the centralized decision, so the price discount model can coordinate the profit of the supply chain as a whole and increase the total profit of the members of the supply chain under the decentralized decision.
4.2. Compensation Strategy Models. In the dual-channel supply chain environment, manufacturers have all the online and offline customers, occupying the absolute dominant position in the market. In order to coordinate the interests of dual-channel members, a compensation strategy model is established. In order to strengthen the cooperation between the two sides, the manufacturer compensates the retailer with the order from the direct online channel according to the proportion of $\theta$. Based on the profit function of manufacturers and retailers in the decentralized scenario, it can be seen that the profit function of manufacturers and retailers in the compensation strategy model is 


$$
\left\{\begin{array}{l}
\pi_{r}^{B}=\left(p_{r}-w\right) \times D_{r}+\left(p_{d}-w\right) \times \theta \times D_{d}-R_{r} \times t_{r}+R_{r} \times v, \\
\pi_{d}^{B}=\left(p_{d}-c\right) \times(1-\theta) \times D_{d}+(w-c) \times\left(D_{r}+\theta \times D_{d}\right)-R_{d} \times t_{d}+R_{d} \times v .
\end{array}\right.
$$

Similarly, by using the Stackelberg game to solve the decentralized decision model, the optimal sales price of the retailer can be obtained:

$$
p_{r}^{B^{*}}=\frac{a s+w(1-\alpha \theta)+\alpha p_{d}(1+\theta)+\beta t_{r}}{2} \frac{n !}{r !(n-r) !} .
$$

Let $p_{r}^{B^{*}}=p_{r}^{j^{*}}$ and the optimal sales price of the retailer under the compensation strategy be equal to the optimal sales price of the retailer under the centralized decision; we can get

$$
\theta=\frac{b \beta^{2}(1-\alpha)+4 b \psi\left(\alpha^{2}-1\right)+\alpha \beta \psi[2 a(1-s)+2 c(\alpha-1)-v \beta]}{b \beta^{2}(\alpha-1)+\beta \psi[2 a(1-s)+2 c(\alpha-1)-v \beta]} .
$$

By using the method of maximizing profits based on decentralized decision-making, formula (34) is substituted into (32) to obtain the optimal selling price, return price, and wholesale price of retailers and manufacturers under the compensation strategy as follows:

$$
\left\{\begin{array}{l}
p_{r}^{B^{*}}=\frac{b+c \beta}{\beta}, \\
p_{d}^{B^{*}}=\frac{\beta^{2}(b+c \beta+v \psi)-4 b \alpha \psi-2 \beta \psi[a(1-s)+c(1+\alpha)]}{A \beta}, \\
t_{r}^{B^{*}}=\frac{2 b \beta^{2}(1-\alpha)+\beta^{3}[c(1-\alpha)-a s]+2 b \psi\left[2\left(\alpha^{2}-1\right)(2+c)+4 a s(1-\alpha)+2 \alpha(2 a-v \beta)\right]}{A \beta^{2}} \\
t_{d}^{B^{*}}=\frac{2 b(1-\alpha)+a \beta(s-1)+c \beta(1-\alpha)+2 v \psi}{A}, \\
w^{B^{*}}=\frac{c \beta^{3}(1+\alpha)+\alpha \beta^{2}(2 b+v \psi)-4 b \alpha^{2} \psi-2 c \mathrm{H}-4 \psi(b \alpha+c \beta)+2 \alpha \beta \psi[a(s-1)-c]}{A \beta(1+\alpha)} .
\end{array}\right.
$$

The optimal sales, wholesale, and return prices obtained from formulas (34) and (35) are substituted into equation
(32), and the optimal profit of retailers and manufacturers under the compensation strategy is

$$
\left\{\begin{array}{l}
\pi_{r}^{B^{*}}=\frac{1}{A^{2} \beta^{2}}\left\{\alpha \beta^{2} \psi^{2}[2 a(s-1)-2 c(\alpha-1)+v \beta]^{2}+2 b^{2}(\alpha-1)\left[\beta^{4}-6 \beta^{2} \psi(1+\alpha)+8 \psi^{2}(1+\alpha)^{2}\right]\right. \\
+c b \beta(\alpha-1)\left[\beta^{4}-6 \beta^{2} \psi(1+\alpha)+8 \psi^{2}\left(2 \alpha^{2}+\alpha+1\right)\right]+\left[\beta^{2}(1-3 \alpha)+4 \psi\left(2 \alpha^{2}+\alpha-1\right)\right] 2 a b \beta \psi \\
\left.-a b s \beta\left[\beta^{4}+2 \beta^{2} \psi(3 \alpha-5)-8 \psi^{2}\left(2 \alpha^{2}+\alpha-3\right)\right]-b v \beta^{2}\left[\beta^{4}-\beta^{2} \psi(7+3 \alpha)\right]-4 b v \beta^{2} \psi^{2}\left(2 \alpha^{2}+\alpha+3\right)\right\} \\
\pi_{d}^{B^{*}}=\frac{1}{A^{2} \beta^{2}}\left\{a^{2} \beta^{2} \psi(s-1)^{2}\left[\beta^{2}+4 \psi(\alpha-1)\right]+8 b^{2} \alpha \psi(\alpha-1)\left[-\beta^{2}+2 \psi(\alpha+1)\right]-\left[4 \psi-\beta^{2}(\alpha+1)\right] v^{2} \beta^{2} \psi^{2}\right. \\
+c^{2} \beta^{2} \psi(\alpha-1)^{2}\left[\beta^{2}+4 \psi(\alpha-1)\right]-c v \beta^{3} \psi(\alpha-1)\left[\beta^{2}+4 \psi(\alpha-1)\right] \\
+a \beta^{3} \psi(s-1)[v \beta-2 c(\alpha-1)]\left[\beta^{2}+4 \psi(\alpha-1)\right]+b \beta\left[\beta^{4}+2 \beta^{2} \psi(\alpha-3)+8 \psi^{2}\left(1+\alpha-2 \alpha^{2}\right)\right](s-1)(a-c) \\
\left.+b v \beta^{2}\left[\beta^{4}+\beta^{2} \psi(\alpha-7)+4 \psi^{2}\left(3+\alpha-2 \alpha^{2}\right)\right]\right\}
\end{array}\right.
$$


Under the compensation strategy, the overall optimal profit of the supply chain is

$$
\pi^{B^{*}}=\pi_{r}^{B^{*}}+\pi_{d}^{B^{*}}=\frac{E}{A \beta^{2}} .
$$

According to formula (37), the overall optimal profit of the supply chain under the compensation strategy model is equal to the overall optimal profit of the supply chain under the centralized decision, so the compensation strategy model can coordinate the overall profit of the supply chain under the decentralized decision and increase the overall profit of the supply chain.

\section{Numerical Analysis and Comparison of the Two Models}

5.1. Numerical Analysis. The relevant parameters are set as follows: the potential market demand $a=1000$, the channel return quantity $b=10$, the manufacturer's production cost $c=20$, and the unit residual value $v=2$. When $\alpha, \beta$, and $\psi$ change, respectively, the values of each parameter change as shown in Tables 2 and 3 and Figures 2-4.

In Figures 2-4, " $\boldsymbol{\nabla}$ " represents the optimal profit of the centralized decision, " $\square$ " represents the optimal profit of the decentralized decision, "๑" represents the optimal profit of the price discount, and " $\boldsymbol{\nabla}$ " represents the optimal profit of the compensation strategy.

Proposition 1. Set $s=0.5, a=1000, c=20, \beta=0.5, b=10$, $\psi=3$, and $v=2$; $\alpha$ takes 8 points at intervals of 0.1 on the interval [0.1-0.8]. When $\alpha$ changes, the changes of the values of each parameter are shown in Table 2 and Figure 2.

As can be seen from Table 2 and Figure 2, when the representation rate $\alpha$ of the mutual influence of dual-channel products changes, the overall profit of retailers, manufacturers, and supply chains will be affected. It can be seen from Table 2 that, after the coordination of price discount and compensation strategy, the overall optimal profit of the supply chain under the decentralized decision is equal to the overall optimal profit under the centralized decision, which verifies the correctness of equations (32) and (36).

Figure 2(a) shows the changes of the manufacturer's profit optimal value under the decentralized decision, price discount model, and compensation strategy model, indicating that when $\alpha$ changes within the range, the optimal profit of the price discount model and compensation strategy model is much larger than that under the decentralized decision, proving the effectiveness of the two contracts. At the same time, the price discount model can better coordinate the profit changes in this range so that the manufacturer can obtain a larger profit value.

Figure 2(b) shows the changes of the optimal profit value of retailers under decentralized decision-making, price discount model, and compensation strategy model, indicating that the compensation strategy model can make retailers obtain more profits than the price discount model when $\alpha$ changes within the interval. The change of $\alpha$ has the greatest impact on the optimal profit of retailers under the decentralized decision; when $\alpha=0.2$, the retailer can obtain the optimal profit under the decentralized decision.

Figure 2(c) shows the changes of the overall optimal profit value of the supply chain under the centralized decision, decentralized decision, price discount model, and compensation strategy model. It is shown that when $\alpha$ changes within the range, the optimal profit of the whole supply chain under the centralized decision model, the price discount model, and the compensation strategy model is equal to and far greater than the optimal profit under the decentralized decision. When $\alpha$ changes within the range, the overall profit of the supply chain shows a slow growth trend in the case of centralized decisionmaking, while the profit is unstable in the case of decentralized decision-making and shows a decreasing trend after 0.2 .

Proposition 2. Set $s=0.5, a=1000, c=20, \alpha=0.5, b=10$, $\psi=3$, and $v=2 ; \beta$ takes 8 points at intervals of 0.1 on the interval [0.1-0.8]. When $\beta$ changes, the changes of the values of each parameter are shown in Table 3 and Figure 3.

As can be seen from Table 3 and Figure 3, when the change rate $\beta$ of market demand on product return price changes in dual channels, the overall profit of retailers, manufacturers, and supply chains will change accordingly.

Figure 3(a) shows the change trend of manufacturers' optimal profit under decentralized decision-making, price discount model, and compensation strategy model when the change rate of product return price is changed by market demand. When $\beta$ changes in this range, the manufacturers' optimal profit under the price discount model is much larger than the optimal profit under the decentralized decision and compensation strategy. The optimal profit under the decentralized decision is negative and fluctuates greatly, and the optimal profit at $\beta=0.2$ is the lowest.

Figure 3(b) shows the changing trend of retailers' optimal profit under decentralized decision-making, price discount model, and compensation strategy model when $\beta$ changes. Under the compensation strategy, retailers' optimal profit is better than the price discount model. When $\beta$ varies from 0.1 to 0.4 , neither of the two decision models can give full play to its value. The compensation strategy plays a greater role when $\beta$ changes between 0.4 and 0.8 .

Figure 3(c) shows the optimal profit variation trend of the whole supply chain under the decentralized decision, price discount model, and compensation strategy model when $\beta$ changes. The optimal values of the centralized decision, the price discount model, and the compensation strategy model are the same within the change interval of $\beta$, showing a decreasing trend, and both of them are far greater than the optimal profit value under the decentralized decision.

Proposition 3. Set $s=0.5=0.5, a=1000, c=20, \alpha=0.5$, $b=10, \beta=0.5$, and $v=2 ; \psi$ takes 8 points at intervals of 0.5 on the interval [5-9]. When the value of $\psi$ changes, the value of other parameters will also change, as shown in Table 4 and Figure 4.

As can be seen from Table 4 and Figure 4, when the return amount of the online direct selling channel changes 
TABLE 2: The optimal profit when $\alpha$ changes (unit: ten thousand RMB).

\begin{tabular}{llllllllll}
\hline$\alpha$ & $\pi^{j^{*}}$ & $\pi_{r}^{f^{*}}$ & $\pi_{d}^{f^{*}}$ & $\pi^{f^{*}}$ & $\pi_{r}^{z^{*}}$ & $\pi_{d}^{z^{*}}$ & $\pi^{z^{*}}$ & $\pi_{r}^{B^{*}}$ & $\pi_{d}^{B^{*}}$ \\
\hline 0.1 & 6.92 & 1.84 & -1.36 & 0.48 & 0.98 & 5.94 & 6.92 & 1.09 & 5.83 \\
0.2 & 7.07 & 6.49 & -0.58 & 5.91 & 1.17 & 5.90 & 7.07 & 1.78 & 5.29 \\
0.3 & 7.23 & 5.03 & -0.37 & 4.66 & 1.51 & 5.72 & 7.23 & 2.50 & 4.73 \\
0.4 & 7.39 & 3.86 & -0.27 & 3.59 & 1.99 & 5.40 & 7.39 & 3.26 & 4.13 \\
0.5 & 7.54 & 3.21 & -0.22 & 2.99 & 2.62 & 4.92 & 7.54 & 4.05 & 3.49 \\
0.6 & 7.71 & 2.80 & -0.18 & 2.62 & 3.43 & 4.28 & 7.71 & 4.88 & 2.83 \\
0.7 & 7.87 & 2.51 & -0.15 & 2.36 & 4.41 & 3.46 & 7.87 & 5.73 & 2.13 \\
0.8 & 8.03 & 2.31 & -0.13 & 2.18 & 5.58 & 2.45 & 8.03 & 6.63 & 7.71 \\
\hline
\end{tabular}

TABLE 3: The optimal profit when $\beta$ changes (unit: ten thousand RMB).

\begin{tabular}{|c|c|c|c|c|c|c|c|c|c|c|}
\hline$\beta$ & $\pi^{j^{*}}$ & $\pi_{r}^{f^{*}}$ & $\pi_{d}^{f^{*}}$ & $\pi^{f^{*}}$ & $\pi_{r}^{z^{*}}$ & $\pi_{d}^{z^{*}}$ & $\pi^{z^{*}}$ & $\pi_{r}^{B^{*}}$ & $\pi_{d}^{B^{*}}$ & $\pi^{B^{*}}$ \\
\hline 0.1 & 12.60 & 2.17 & -1.48 & 0.69 & 6.08 & 6.52 & 12.60 & 6.78 & 5.82 & 12.60 \\
\hline 0.2 & 9.50 & 9.09 & -6.14 & 2.95 & 4.03 & 5.47 & 9.50 & 5.18 & 4.32 & 9.50 \\
\hline 0.3 & 8.40 & 5.66 & -3.81 & 1.85 & 3.25 & 5.15 & 8.40 & 4.55 & 3.85 & 8.40 \\
\hline 0.4 & 7.85 & 4.10 & -2.75 & 1.35 & 2.85 & 5.00 & 7.85 & 4.23 & 3.62 & 7.85 \\
\hline 0.5 & 7.54 & 3.21 & -2.15 & 1.06 & 2.62 & 4.92 & 7.54 & 4.05 & 3.49 & 7.54 \\
\hline 0.6 & 7.36 & 2.63 & -1.76 & 0.87 & 2.48 & 4.88 & 7.36 & 3.96 & 3.40 & 7.36 \\
\hline 0.7 & 7.26 & 2.23 & -1.49 & 0.74 & 2.40 & 4.86 & 7.26 & 3.92 & 3.34 & 7.26 \\
\hline 0.8 & 7.21 & 1.93 & -1.29 & 0.64 & 2.34 & 4.87 & 7.21 & 3.92 & 3.29 & 7.21 \\
\hline
\end{tabular}

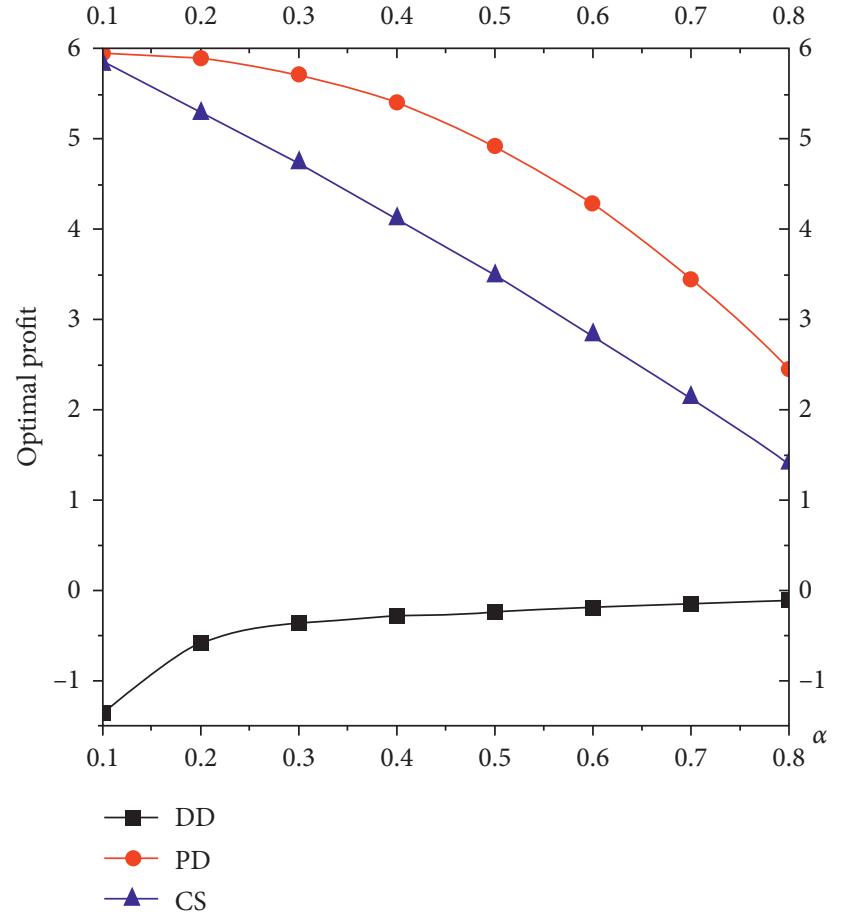

(a)

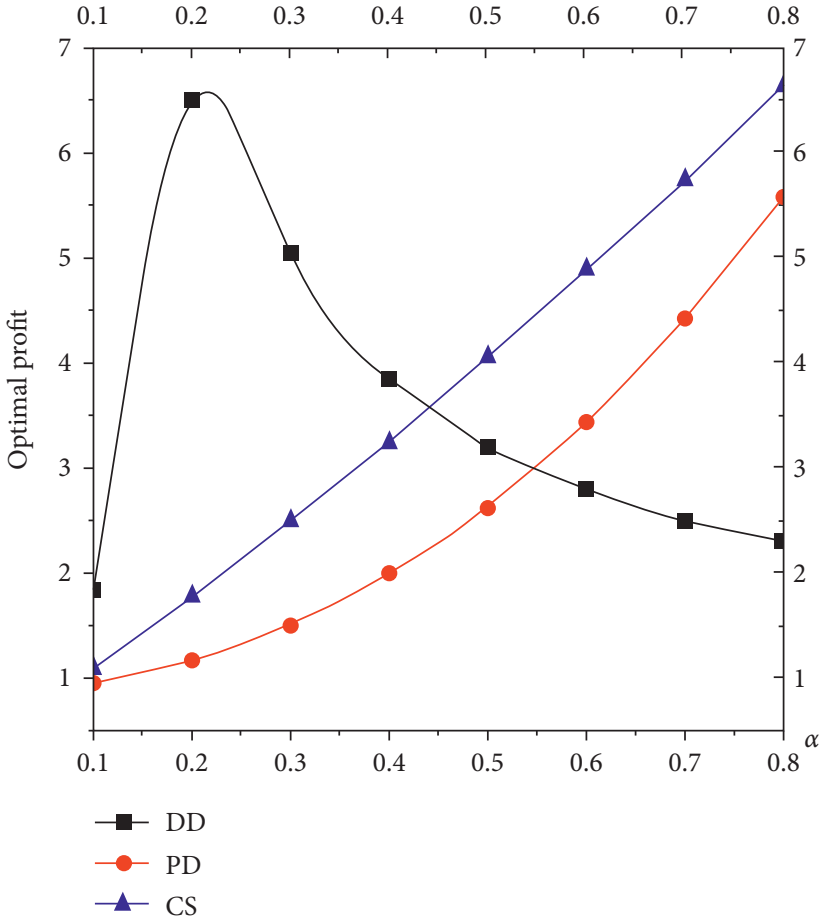

(b)

FIgURE 2: Continued. 


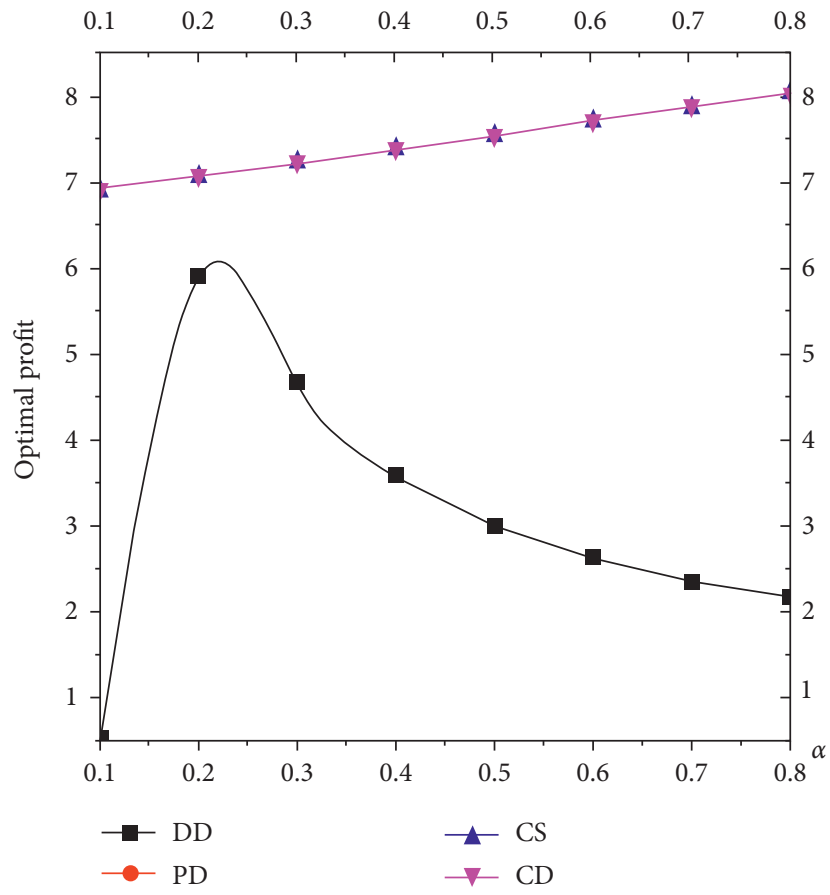

(c)

Figure 2: The change diagram of the optimal profit value when $\alpha$ changes. (a) The change of manufacturers' profits. (b) The change of retailers' profits. (c) The change of the total supply chain profit.
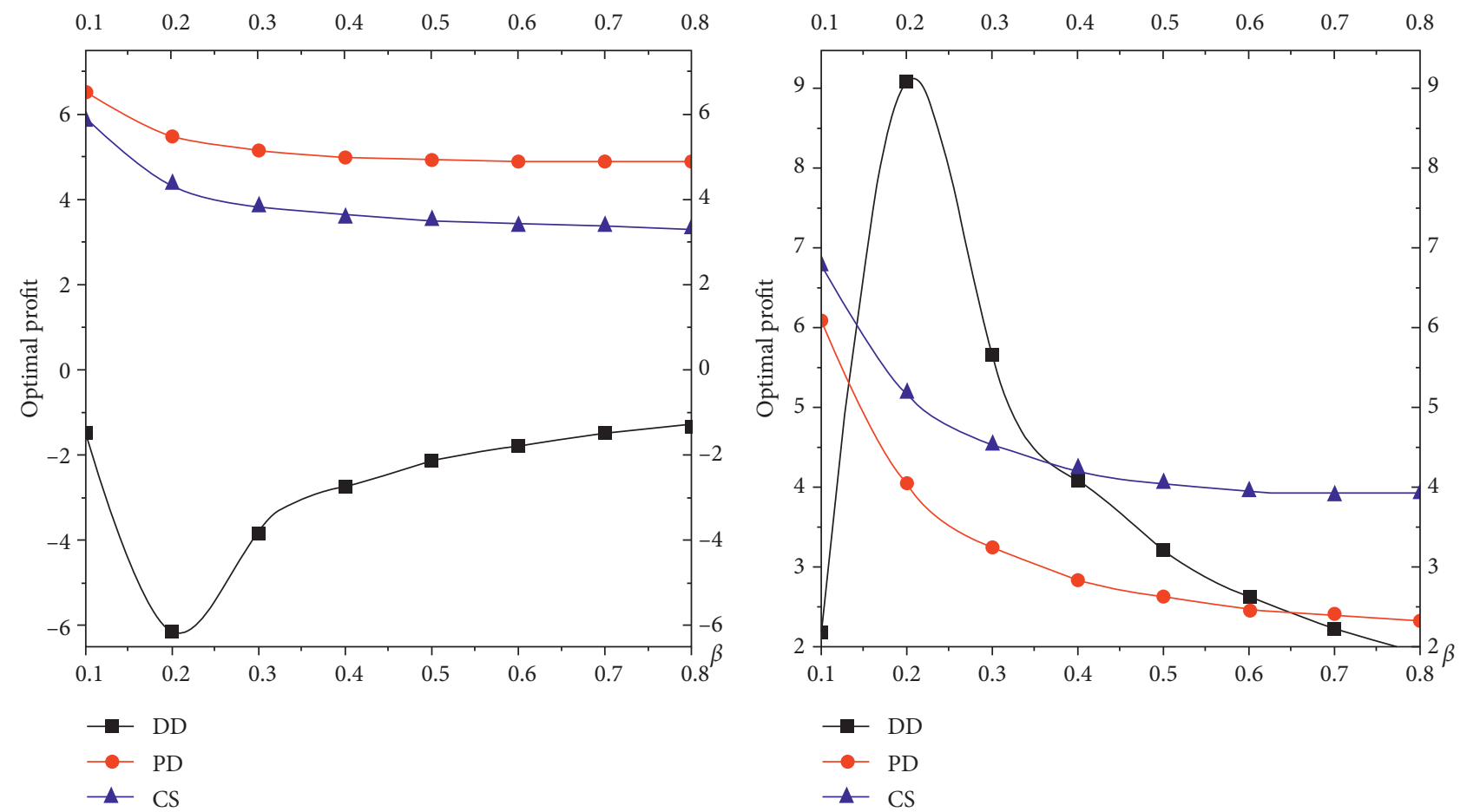

(a)

(b)

Figure 3: Continued. 


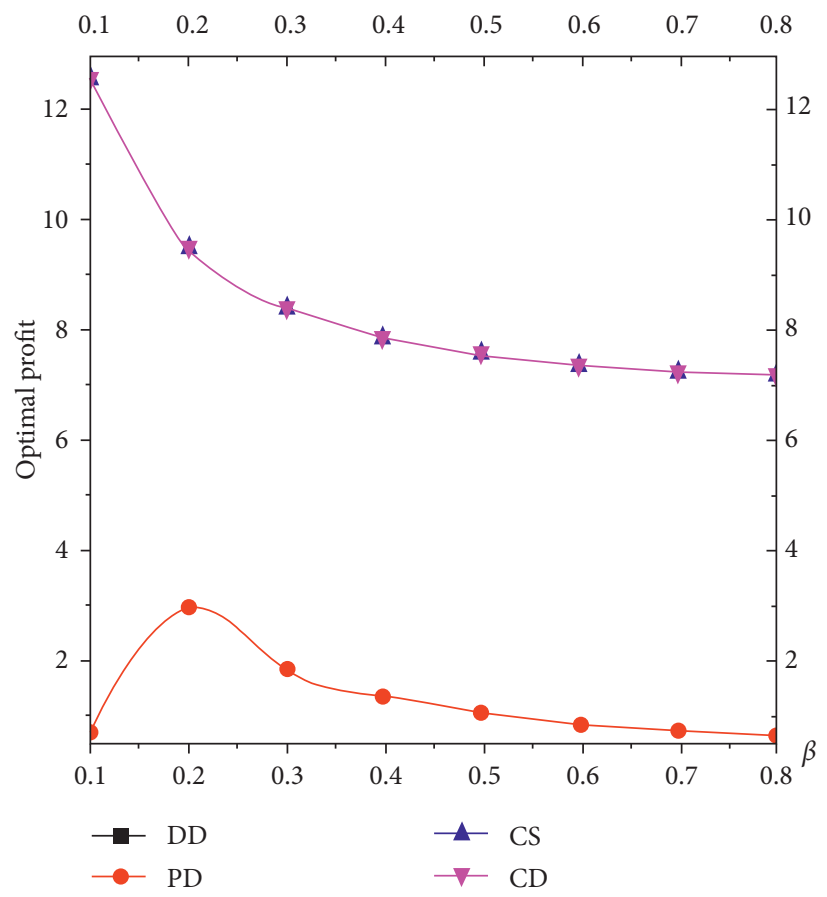

(c)

Figure 3: The change diagram of the optimal profit value when $\beta$ changes. (a) The change of manufacturers' profits. (b) The change of retailers' profits. (c) The change of the total supply chain profit.

TABle 4: The optimal profit when $\psi$ changes (unit: ten thousand RMB).

\begin{tabular}{llllllllll}
\hline$\psi$ & $\pi^{j^{*}}$ & $\pi_{r}^{f^{*}}$ & $\pi_{d}^{f^{*}}$ & $\pi^{f^{*}}$ & $\pi_{r}^{z^{*}}$ & $\pi_{d}^{z^{*}}$ & $\pi^{z^{*}}$ & $\pi_{r}^{B^{*}}$ & $\pi_{d}^{B^{*}}$ \\
\hline 5.0 & 7.50 & 3.21 & -2.15 & 1.06 & 2.60 & 4.90 & 7.50 & 4.00 & 3.50 \\
5.5 & 7.49 & 3.21 & -2.15 & 1.06 & 2.59 & 4.90 & 7.49 & 3.99 & 3.50 \\
6.0 & 7.48 & 3.21 & -2.15 & 1.06 & 2.59 & 4.89 & 7.48 & 3.98 & 3.50 \\
6.5 & 7.48 & 3.21 & -2.15 & 1.06 & 2.59 & 4.89 & 7.48 & 3.98 & 3.50 \\
7.0 & 7.48 & 3.21 & -2.16 & 1.05 & 2.59 & 4.89 & 7.48 & 3.98 & 3.50 \\
7.5 & 7.47 & 3.21 & -2.16 & 1.05 & 2.58 & 4.89 & 7.47 & 3.98 & 3.50 \\
8.0 & 7.47 & 3.22 & -2.16 & 1.06 & 2.58 & 4.89 & 7.47 & 3.97 & 3.50 \\
8.5 & 7.46 & 3.22 & -2.16 & 1.06 & 2.58 & 4.88 & 7.46 & 3.96 & 3.50 \\
\hline
\end{tabular}

with the change rate of return price on the interval, the overall profit of retailers, manufacturers, and supply chains will also change accordingly.

Figure 4(a) shows the variation of the optimal profit value with $\psi$ under the decentralized decision, price discount model, and compensation strategy model. When $\psi$ changes within the range, the variation range of the manufacturers' optimal profit under the three conditions is small, and the manufacturers' optimal profit under the two coordination models is larger than the optimal profit under the decentralized decision, and the price discount model can play a good role.

Figure 4(b) shows that the optimal profit of retailers varies with a small range under decentralized decisionmaking, price discount model, and compensation strategy model, and the optimal profit of retailers under the compensation strategy model is relatively large.

Figure 4(c) shows that the optimal profit value of the whole supply chain is equal under the centralized decision, price discount model, and compensation strategy model. When $\psi$ changes within the range, the optimal profit value changes slightly, and the overall optimal profit of the supply chain under the two coordination decision models is much larger than that under the decentralized decision model.

5.2. The Comparison of the Two Models. Theoretical analysis was carried out for the two models, and the changes of the optimal profit value of the two models were analyzed when $\alpha$ (the rate of interaction between two-channel products), $\beta$ (the rate at which market demand changes the return price of products in dual channels), and $\psi$ (the change rate of the return amount of the online direct selling channel with the return price) were changed by combining relevant data and charts.

(1) By analyzing the data in Table 2 and the changing trend in Figure 2, it can be seen that when $\alpha$ changes, under the price discount model, the manufacturers' 

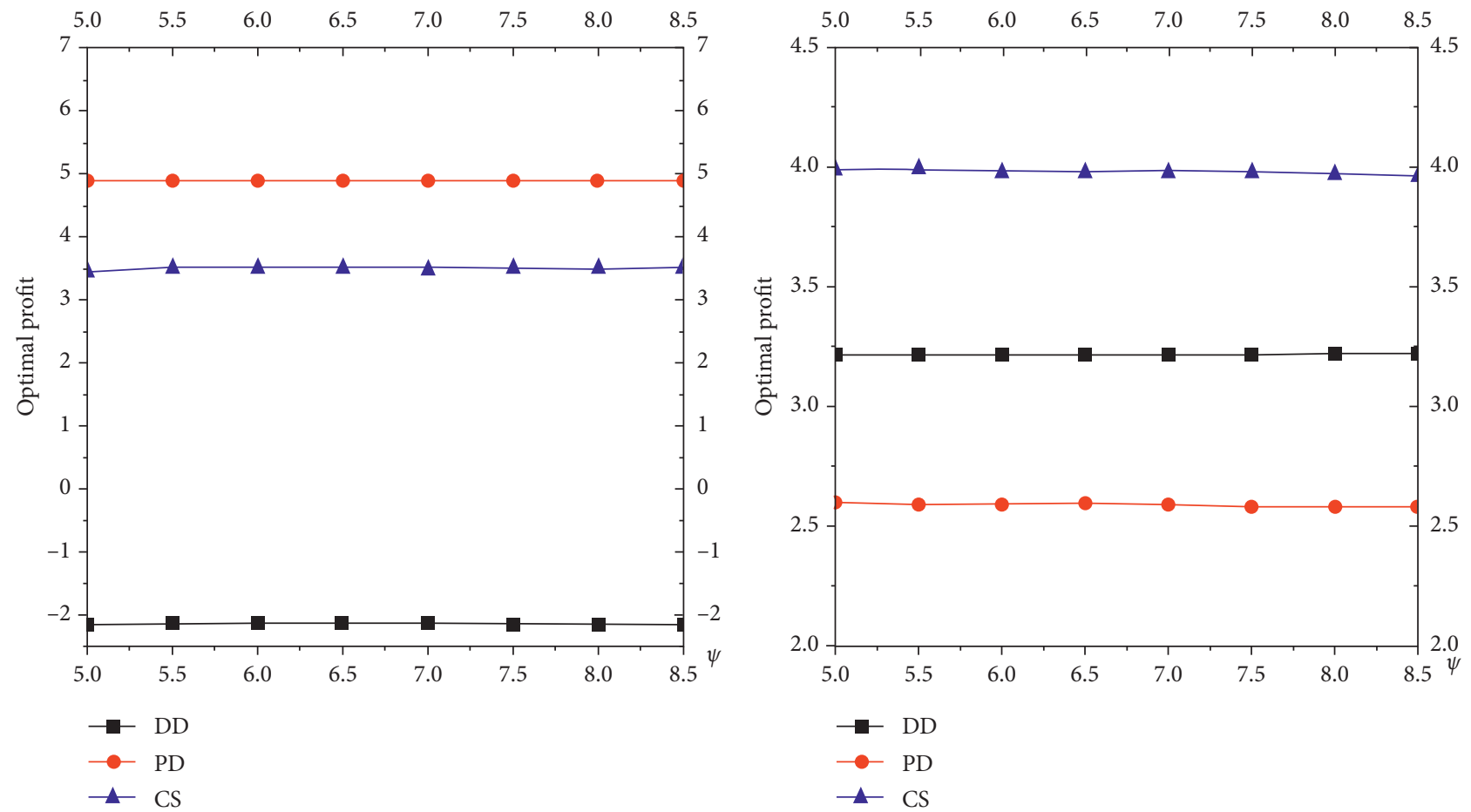

(a)

(b)

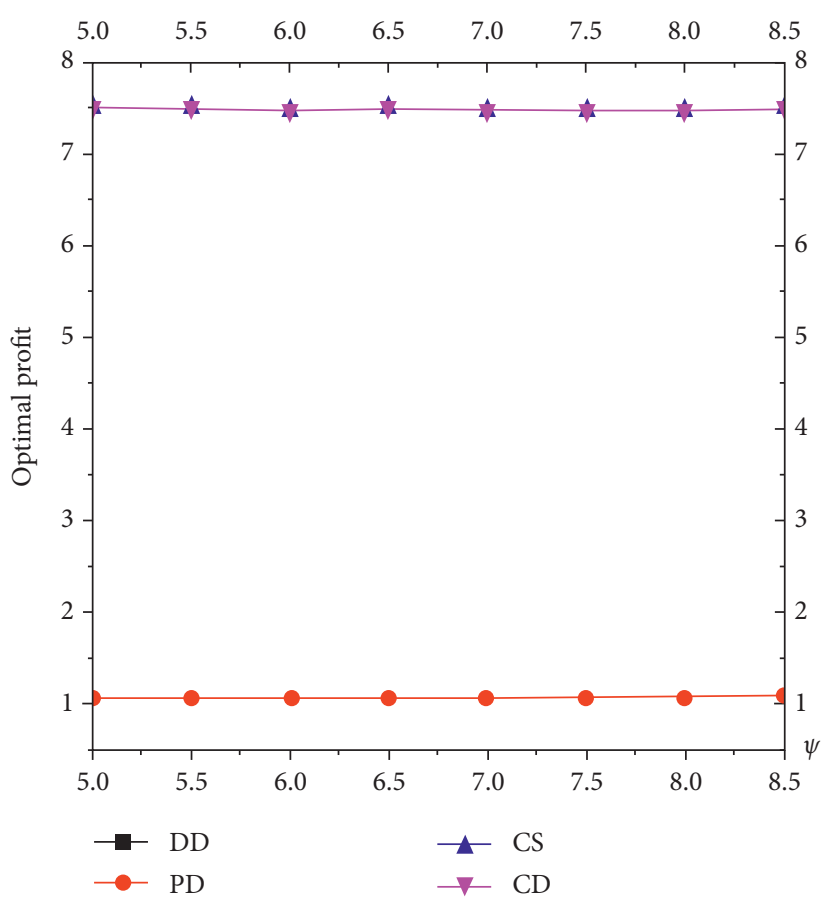

(c)

FIgURE 4: The change diagram of the optimal profit value when $\psi$ changes. (a) The change of manufacturers' profits. (b) The change of retailers' profits. (c) The change of the total supply chain profit.

optimal profit is larger; under the compensation strategy model, the retailers' optimal profit is larger.

(2) By analyzing the data in Table 3 and changing trends in Figure 3, we can see that when $\beta$ changes, the price discount model is still more favorable for manufacturers to obtain optimal profits, while the compensation strategy model is more favorable for retailers to obtain optimal profits.

(3) By analyzing the data in Table 4 and the changing trend in Figure 4, it can be seen that when $\psi$ changes, the same situation occurs. Therefore, by comparing the two models, we can see that the price 
discount model is better for manufacturers to maximize profits, and the compensation strategy model is more favorable for retailers than the price discount model.

From Tables 2-4 and Figures 2-4, it can be seen that the price discount model and compensation strategy model can play a good coordination role and make the whole supply chain achieve profit optimization.

\section{Conclusion and Discussion}

By studying the return situation of a manufacturer-led dual-channel supply chain in a competitive market environment, considering the offline retail customers to purchase the product loyalty coefficient, dual channels influence each other between the product rate, the change rate of market demand to return price, and the rate at which the amount of return in an online channel changes with the return price and other factors, the price discount model and the compensation strategy model were established in order to coordinate the profits of manufacturers, retailers, and supply chain as a whole after return and make the profits maximize. Also the validity of the model should be confirmed through a numerical example and the method of chart analysis. The results show the following: (1) in the dual-channel supply chain environment, the profit of the centralized decision return model is larger than that of the decentralized decision return model. Profit coordination can be realized through the price discount model and compensation strategy model. The overall optimal profit of the supply chain in the decentralized decision-making scenario is equal to the overall optimal profit of the supply chain in the centralized decision-making scenario, which maximizes the profit of the dual-channel supply chain. (2) When the change rate of mutual influence between products of the dual-channel supply chain, the change rate of market demand on product return price, and the change rate of online direct sales channel's return amount with return price are changed, the overall profit of retailers, manufacturers, and supply chain will be affected, and the former two are more affected than the latter. (3) When the conditions of a manufacturer-led dual-channel supply chain are the same, the price discount model is more favorable for manufacturers to maximize profits, while the compensation strategy model is more helpful for retailers to maximize profits.

This paper mainly applies price discount and compensation strategy to solve the return problem of the dualchannel supply chain and makes use of supply chain coordination decision-making to make the overall profit of the supply chain in the return scenario reach the optimal value. In the aspect of theory, it enriches supply chain decision theory and optimizes supply chain pricing decision. In the aspect of practice, it can be widely used to solve the pricing and profit coordination decision-making problem of the enterprise's dual-channel supply chain operation mode, which has wide applicability and strong application value. When the market demand is random, the cross-return and dual-channel supply chain pricing decision under the big data environment need to be further studied.

\section{Data Availability}

Suppliers and retailers are rational decision-makers who make decisions based on the principle of revenue maximization. The parameters selected in this paper meet the above assumptions. And more abundant management inspiration could be obtained through numerical simulation.

\section{Conflicts of Interest}

The authors declare that there are no conflicts of interest.

\section{Acknowledgments}

This research was supported by the Natural Science Foundation of China (Grant no. 71662007), Guangxi Aviation Logistics Research Centre Project (Grant nos. 2017KFJJHKWL02 and 19KFJJHKWL06), the Natural Science Foundation of Guangxi (Grant no. 2018GXNSFAA281311), and Innovation Project of GUET Graduate Education (Grant no. 2020YCXS069). The authors thank all the references' authors.

\section{References}

[1] S. K. Mukhopadhyay and R. Setaputra, "A dynamic model for optimal design quality and return policies," European Journal of Operational Research, vol. 180, no. 3, pp. 1144-1154, 2007.

[2] K. Samar and R. S. Mukhopadhyay, "Reverse logistics in e-business optimal price and return policy," International Journal of Physical Distribution\& Logistics Management, vol. 34, no. 1, pp. 70-88, 2004.

[3] C. H. Lee, "Coordinated stocking, clearance sales, and return policies for a supply chain," European Journal of Operational Research, vol. 131, no. 3, pp. 491-513, 2001.

[4] A. A. Taleizadeh, V. R. Soleymanfar, and T.-M. Choi, "Optimal pricing and alliance strategy in a retailer-led supply chain with the return policy: a game-theoretic analysis," Information Sciences, vol. 420, pp. 466-489, 2017.

[5] N. Zaarour, M. M. Solomon, and H. Min, "Optimal collection period for returned products in the reverse supply chain," IFAC Proceedings Volumes, vol. 46, no. 9, pp. 123-127, 2013.

[6] U. Melachrinoudis and I. P. L. Png, "Rrturn policies: make money by making good," Sloan Management Review Fall, vol. 29, no. 2, pp. 68-72, 1995.

[7] E. Ofek, Z. Katona, M. Sarvary et al., "“Bricks and clicks”: the impact of product returns on the strategies of multichannel retailers," Marketing Science, vol. 30, no. 1, pp. 42-60, 2011.

[8] B. A. Pasternack, "Optimal pricing ang return policies for perishable commodities," Marketing Science, vol. 21, no. 4, pp. 166-176, 1985.

[9] T. S. Genc and P. De Giovanni, "Optimal return and rebate mechanism in a closed-loop supply chain game," European Journal of Operational Research, vol. 269, no. 2, pp. 661-681, 2018.

[10] R.-T. A. J. F. Mahmoodi and S. Ohmori, "Joint determination of supplier capacity and returner incentives in a closed-loop supply chain," Journal of Cleaner Production, vol. 215, pp. 1351-1361, 2019. 
[11] M. Noori-daryan and A. A. Taleizadeh, "Optimizing pricing and ordering strategies in a three-level supply chain under return policy," Journal of Industrial Engineering International, vol. 15, no. 1, pp. 73-80, 2019.

[12] R. Taleizadeh, M. Y. Jaber, and S. M. Aljazzar, "A profit maximization for a reverse logistics dual-channel supply chain with a return policy," Computers \& Industrial Engineering, vol. 106, pp. 58-82, 2017.

[13] M. Radhi and G. Zhang, "Optimal cross-channel return policy in dual-channel retailing systems," International Journal of Production Economics, vol. 210, pp. 184-198, 2019.

[14] S. H. Yoo, "Product quality and return policy in a supply chain under risk aversion of a supplier," International Journal of Production Economics, vol. 154, pp. 146-155, 2014.

[15] E. Masoudipour, H. Amirian, and R. Sahraeian, "A novel closed-loop supply chain based on the quality of returned products," Journal of Cleaner Production, vol. 151, pp. 344$355,2017$.

[16] L. Amodeo and M. Godichaud, "Efficient multi-objective optimization of supply chain with returned products," Journal of Manufacturing Systems, vol. 37, no. 3, pp. 683-691, 2015. 